\title{
Intusscuception in an infant - A case report
}

\author{
Sathialakshmi $\mathbf{V}^{1, *}$, Rakesh Ranjan $\mathrm{S}^{2}$, Suajtha Nagari ${ }^{3}$, Swayam Jothi $\mathrm{S}^{4}$ \\ ${ }^{1,2}$ Professor, ${ }^{3}$ Lecturer, ${ }^{4}$ Professor \& HOD, Dept. of Anatomy, ${ }^{1,3,4}$ Shri Sathya Sai Medical College and Research Institute, Tamil \\ Nadu, ${ }^{2}$ Government Medical College, Patna, Bihar, India
}

*Corresponding Author:

Email: hemanth.kommuri@gmail.com

\begin{abstract}
Intussusception is characterized by abdominal pain, vomiting and blood in stools. However, in younger infants it may present with non-classical symptoms such as listlessness, decreased feeding, and being non-specifically unwell.

A Case of intussusception confirmed with the help of an abdominal ultrasound in 5 month old male infant who presented with irritable cry, spasmodic pain, and not taking feeds properly. The purpose of presenting this paper is to suggest a clinical diagnosis of intussusception, and to bring about the awareness of intussusception common in weaning period of very young infants and the latest treatment available which was so simple procedure without any complication and surgery.
\end{abstract}

Keywords: Intussusception, Weaning, Spasmodic.

\section{Introduction}

Intussusception is one of the common surgical emergencies encountered in infancy and early childhood. This is a condition where the proximal segment of the bowel telescopes into the distal segment causing obstruction. It most often involves the terminal ileum and caecum, but may occur anywhere within the small or large bowel.

The cause of intussusception remains still not clear. However, any pathological process that provides a lead point within the lumen of the bowel may cause intussusception. A lead point can be defined as any projection or lesion within the lumen of the bowel, ${ }^{1}$ which can be affected by peristalsis. Most commonly, lead points are formed by lymphoid hypertrophy (Peyer's patches). ${ }^{2}$ Other possible lead points may include Meckel's diverticulum, duplication cysts, polyps, and lymphoma. ${ }^{1}$

Intussusception was first described by Barbette of Amsterdam $^{3}$ in 1674. Hunter ${ }^{4}$ in 1789 discussed the surgical pathology of intussusception. The exact year of surgical reduction of intussusception remains controversial 1784 according to Hutchinson but 1672 according to Ashhurst. ${ }^{4}$ In 1876 Hirschsprung first described the reduction of intussusceptions by hydrostatic pressure methods ${ }^{[5]}$. The etiology of this condition is still unknown. However, upper respiratory tract infection and change in the micro-flora of the gut around the weaning period have been implicated in most cases. ${ }^{6,7}$

\section{Case Report}

In the pediatric OP department of our hospital 5 months old male baby was brought by the mother who complained that her baby was irritable, not taking feeds properly with irritable cry and spasmodic pain since two days. History taking conveyed that the baby was weaned just 20 days ago, she also gave history of passing blood and mucus in the stools (Red-currant Jelly Stool)

\section{Diagnosis}

On examination baby was a febrile, not anemic, nothing abnormal was deducted in respiratory and cardio vascular systems. Examination of the abdomen revealed a small lump in the right iliac fossa with tenderness. Apart from routine examinations ultrasound of abdomen was done which revealed jejuno-ileal intussusception.

The baby was admitted in the pediatric ward and conservative treatment was started. The baby was examined by pediatric gastro-enterologist and confirmed the diagnosis. The treatment was started immediately. It was a very simple procedure and the pediatric surgeon was present in the ultrasound suite throughout the procedure. The child was placed on an inflatable plastic enema ring (Fig. 1) connected to a suction device that allows continuous suction of fluid from the enema ring. The criteria for successful reduction were disappearance of the intussusceptum through the ileocecal valve, followed by passage of water and air bubbles from the caecum into the terminal ileum. (Fig. 2).

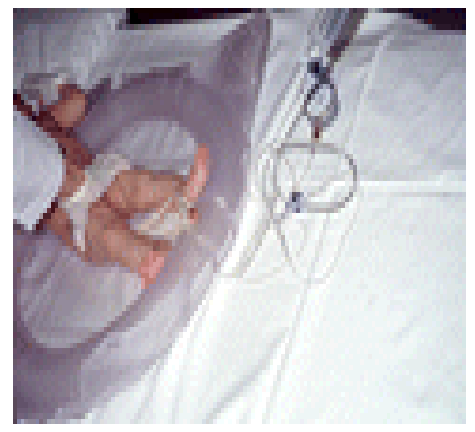

Fig. 1: Showing child is placed on an inflatable plastic enema ring 


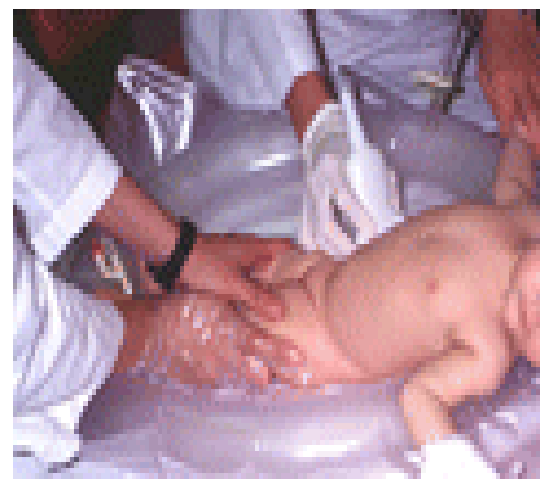

Fig. 2: Showing ultrasonography performed while enema catheter passed

\section{Discussion}

It is one of the most common abdominal emergencies for children less than 3 years of age, with a variable incidence of 0.33 to 2.4 per 1000 live births. ${ }^{1}$ Most cases occur under 12 months of age (beginning of weaning), with over $90 \%$ of cases observed within the first 3 years of life. ${ }^{8,9}$ Common in boys than girls. ${ }^{1}$ The classic triad of symptoms consists of abdominal pain, vomiting and blood in stools.

Severe gastroenteritis may lead to intussusceptions, cystic fibrosis and sickle cell crisis ${ }^{\mathrm{l}}$ are some of the other causes for intussusceptions [10], [11. Foreign body ingestion in young children may lead to intussusception specific caution needs to be taken in the event of multiple magnet ingestion. Untreated intussusceptions are fatal within two to five days. Many authors reported that a lead point in the intestine allows a bowel segment (intussusceptum) with its mesentry to telescope into the adjacent distal segment (intussuscipiens) causing the obstruction. ${ }^{10,12}$ 'Red currant jelly' stool will be seen in patients with intussusceptions due to the strangulations of the intestinal segments causing mucosal bleeding.

Many authors reported the classical clinical features of intussusceptions are abdominal pain, passage of bloody mucoid stool, and palpable abdominal mass, ${ }^{13-15}$ the present case report also showed the same clinical findings.

\section{Conclusion}

Intussusception is common during weaning period of the infant and the latest treatment available is a simple procedure without any complication and surgery.

\section{References}

1. Kapoor T, McGee RG, Karpelowsky J, Su M, Webster AC. Surgical and non-surgical management for intussusception in children (Protocol). Cochrane Database of Systematic Reviews 2013, Issue 10. Art. No.: CD006476. DOI: 10.1002/14651858.CD006476.pub2.

2. Tate J, Simonsen L, Viboud Cm Steiner C, Patel M, Curns A, Parashar U. Trends in Intussusception Hospitalizations Among Infants, 1993-2004: Implications for Monitoring the Safety of the New Rotavirus
Vaccination Program. Pediat 2008;121:1125-32. DOI: 10.1542/peds.2007-1590.

3. Madanur M.A., Mula V.R., Patel D. et al. Periampullary carcinoma presenting as duodenojejunal intussusception: a diagnostic and therapeutic dilemma. Hepatobiliary Pancreat Dis Int 2008;7:658-60.

4. Lewis J.H. Jejunal intussusception of the newborn. Am J Dis Child 1939;58(3):558-63.

5. Bisset III G.S., Kirks D.R.Intussusception in infants and children: diagnosis and therapy. Radiol 1988; 168:14145.

6. Keita M, Barry OT, Doumbouya N, Diallo AF, Youre BM, Balde I. Acute intussusceptions in childhood: Aspects of epidemiology, clinical features and management at children's hospital, donka, guineaconakry. Afr J Paediatr Surg 2006;3(10):1-3.

7. Osifo OD, Evbuomwan I, Osime OO, Mene AO. Paediatric Intussusceptions in Benin City, Nigeria. Afr J Paediatr Surg 2007;4(11):12-5.

8. Beres AL, Baird R, Fung E, Hsieh H, Abou-Khalil M, Gerstle JT. Comparative outcome analysis of the management of pediatric intussusception with or without surgical admission. J Pediat Surg 2014;49:750-2.

9. Beres AL, Baird R. An institutional analysis and systematic review with meta-analysis of pneumatic verses hydrostatic reduction for pediatric intussusception. Surg 2013;154(2):328-34. DOI: 10.1016/j.surg.2013.04.036.

10. Nelson K.A., Hostetler M.A.Alistless infant with vomiting. Hospital Physician 2002;40-6.

11. Turner D., Rickwood A.M.K., Brereton R.J. Intussusception in older children. Arch Dis Child 1980;55:544-6.

12. Kleizen K.J., Hunck A., Draaisma J.M.Th.Neurologic symptoms in children with intussusception. Acta Paediatrica 2009;98:1822-4.

13. Bode CO. Presentation and management outcome of childhood intussusception in Lagos: A prospective study. Afr J Paediatr Surg 2008;5:24-8.

14. Mangete ED, Allison AB. Intussusception in infancy and childhood: An analysis of 69 cases. West Afr J Med 1994;13:87-90.

15. Ugwu BT, Legbo JN, Dakum NK, Yiltok SJ, Mbah N, Uba FA. Childhood intussusception: A 9-year review. Ann Trop Paediatr 2000;20:131-5. 